\title{
A MORPHOLOGICAL STUDY OF ATHEROSCLEROTIC LESIONS OCCURRING AT THE ROOT OF AORTA
}

\author{
TYagi, S. P., M.D*, DadgaR, S. K., M.D.,* \\ HAMEED, S., M.D., D. Path. (London)***
}

\begin{abstract}
While studying morphological changes in heart $1-3 \mathrm{~cm}$ of Aorta was also removed and incidence of atherosclerosis in that portion was studied. In all 110 aortas were examined. Atherosclerotic lesions were observed in 77 aortas $(70.0 \%)$. The incidence increases with the age and beyond 4th decade all the aortas were affected.

Fatty streaks were observed in 2 nd decade involving only $7.5 \%$ of the total intimal surface and reaching to a maximum of $22.2 \%$ in the 3 rd decade. Fibrous plaques involved a small area $(2.6 \%)$ in 3 rd decade, followed by a gradual rise to $9.2 \%$ in 7 th decade. Complicated lesions though occurred in 3rd decade involving $0.7 \%$ surface but a maximum coverage $(4.5 \%)$ was seen in 7 th decade.

These findings have been discussed in the light of observations of other workers. There is slow progression of fibrous plaques and paucity of complicated lesions in Indians as compared to white population. The study has further revealed that the encrustation of mural thrombi is probably the main basis for the progression of the atheromatous lesion.
\end{abstract}

\begin{abstract}
$\mathbf{A}^{\mathrm{T}}$
THEROSCLEROSIS is fairly common in India though the severity and extent of the lesion is not so great as is observed in Western countries or the white population!-8 The early lesions (fatty streaks) show much less geographical and racial variation than do the raised plaques. The area involved by plaques reaches much higher figures in white races and western-type civilizations than in coloured races and Africans. Oriental, South American and so called underdeveloped communities?

In most of the studies carried out in the past lesions have been described involving the entire aorta. No specific study so far has been made
\end{abstract}

about the incidence and severity of the lesions affecting th: root of the aorta.

The present communication deals with the observations on the occurrence of atherosclerosis at the root of the aorta or supravalvular portion in Aligarh District, Uttar Pradesh, India.

\section{MATERIALS AND METHODS}

Specimens of heart were collected from medico-legal postmortems for a study of ventricular weights and their importance in assessing cardiac hypertrophy. While removing the heart $1-3 \mathrm{cms}$ of aorta was left attached to it in order to assess the incidence of atherosclerosis. In all

* Reader in Pathology,

** Research Fellow under the Indo-Afghan Cultural Exchange Programme.

*** Professor \& Head of the Department of Pathology

From the Section of Morbid Anatomy, Department of Pathology, Jawaharlal Nehru Medical College, Aligarh

Muslim University, Aligarh-202001, U.P., India

Address for Correspondence: Dr. Som Prakash Tyagi, Reader in Pathology, Jawaharlal Nehru Medical College, Aligarh Muslim University, Aligarh-202001, INDIA 
TABLE I SHOWING INCIDENCE OF ATHEROSCLEROSIS AT THE ROOT OF AORTA

\begin{tabular}{cccc}
\hline \hline Age Group in Years & $\begin{array}{c}\text { Total Number } \\
\text { of Aortas } \\
\text { Studied }\end{array}$ & \multicolumn{2}{c}{ Aortas Showing A therosclerosis } \\
\hline Less than 10 & 2 & Number & Percentage \\
$11-20$ & 12 & 0 & 0.0 \\
$21-30$ & 37 & 23 & 25.0 \\
$31-40$ & 28 & 20 & 62.2 \\
$41-50$ & 14 & 14 & 100.0 \\
$51-60$ & 6 & 6 & 100.0 \\
Above 60 & 11 & 11 & 100.0 \\
Total & 110 & 77 & 70.0
\end{tabular}

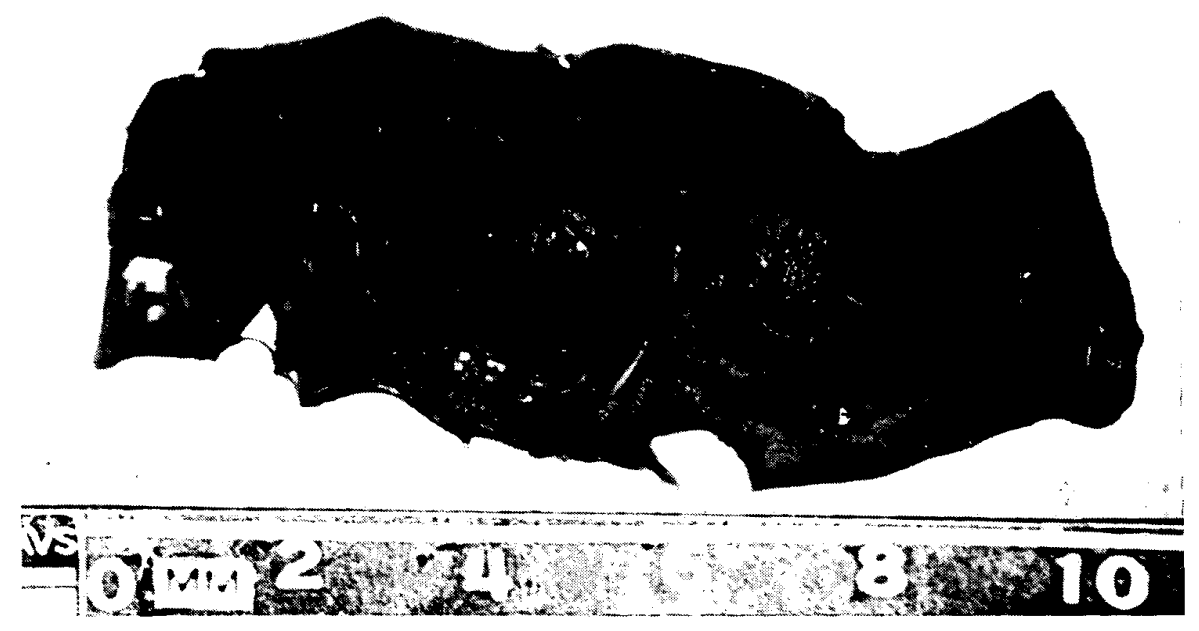

Fig.1. Atheromatous lesion showing fatty streaks, plaques and calcified area (extreme left) involving the root of aorta.

110 specimens from different age groups were studied. The inner surface of the aorta was exposed and stained by the technique described by Holman et al! ${ }^{10}$ The lesions assessed on gross morphology were classified as (i) fatty streaks (ii) fibrous plaques and (iii) complicated lesions according to the recommendations of W.H.O. Study Group. Atleast 3 blocks were taken from the visible or suspected areas. Paraffin sections were stained with haemotoxylin and eosin, Verhoeff's van Gieson stain for elastic fibres, von Kossa for Calcium, Periodic Acid Schiff's (PAS) for mucopolysaccharides and P.T.A.H. for fibrin. Frozen sections were stained with Sudan IV for demonstration for fat.

\section{RESULTS}

\section{Gross Features}

Out of 110 aortas $33(30.0 \%)$ were devoid of any visible atheromatous lesion. The distribution of specimens showing atherosclerosis in relation to various age groups is shown in Table I. The incidence gradually increases with the age till $100 \%$ involvement was observed in 5 th decade and onwards. In some cases all the three types of lesions were seen (Fig. 1).

Fatty streaks were observed in the 2 nd decade involving on an average $7.5 \%$ of the intimal surface and reaching to a maximum of $22.2 \%$ in the 3 rd decade. Later on a gradual fall in the surface area involved was noticed upto 5 th decade (16.6\% of intimal surface). Beyond that a slight 


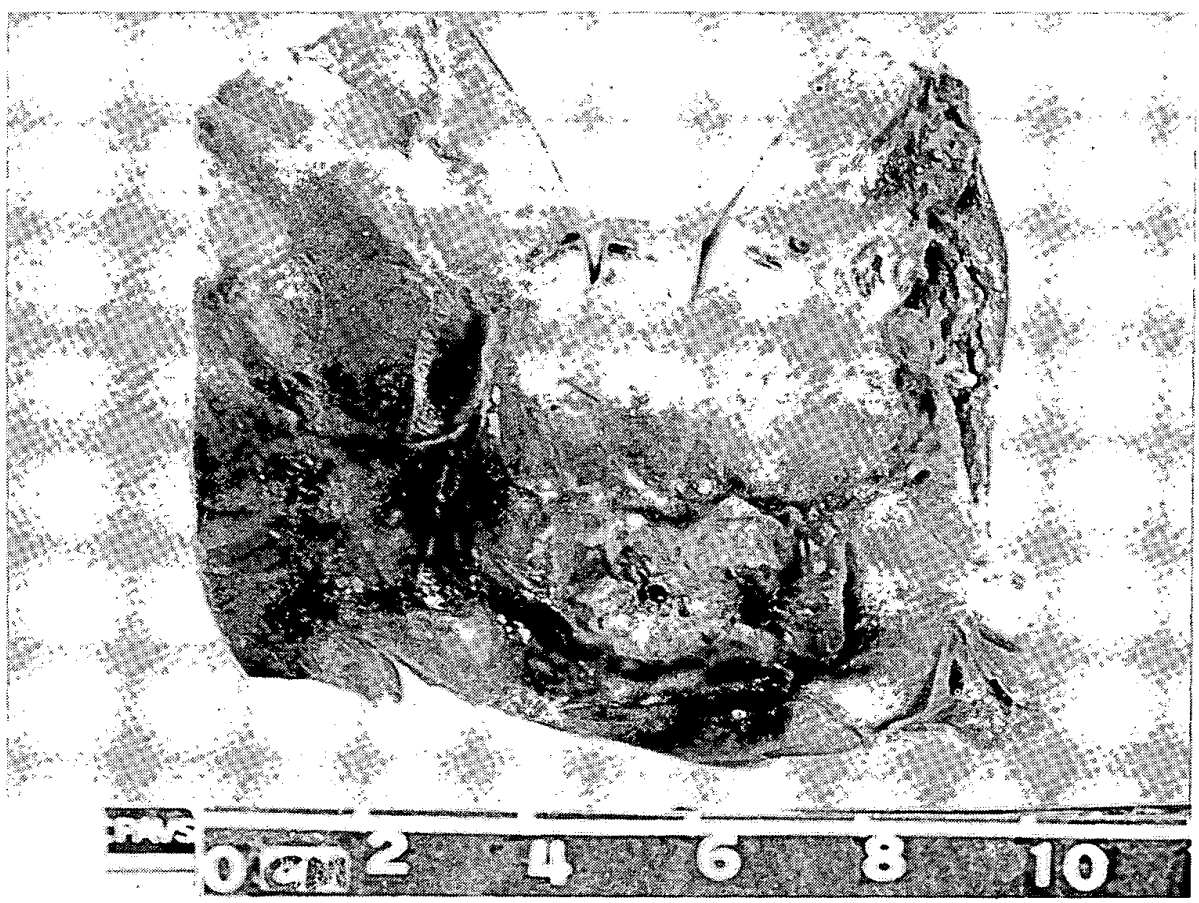

Fig.2. Hardened and calcified aorta with atheromatous ulcer in the lower half (Case no. 102).

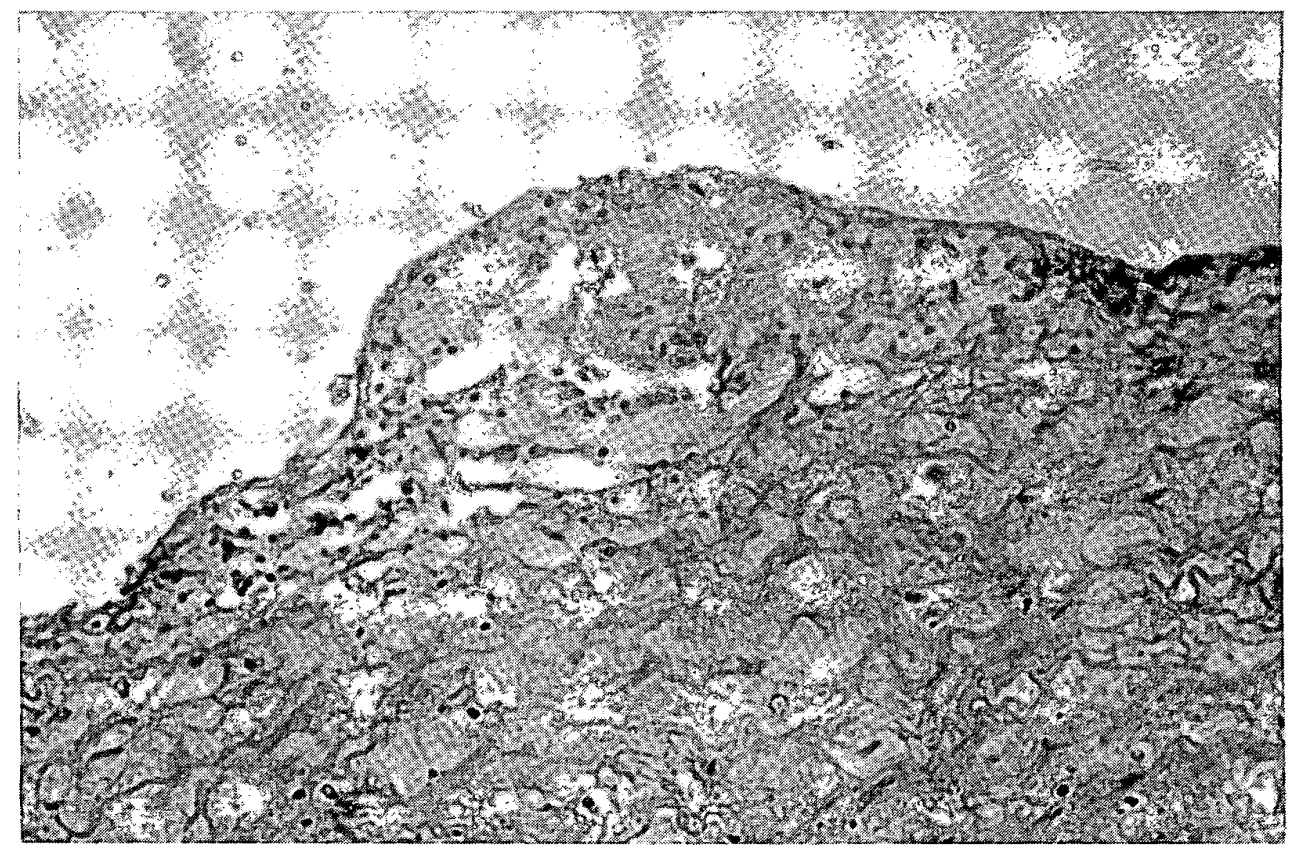

Fig.3. Early fatty streak: Accumulation of lipophages and scanty mononuclear cell infiltration. H. \& E. $\times 160$.

increase to $17.2 \%$ in 7 th decade was observed.

The circumscribed pearly grey fibrous plaques appeared in the 3rd decade involving a very small portion of intimal surface $(2.6 \%)$ and therafter a slow gradual rise was noticed reaching upto $9.2 \%$ intimal surface involvment in 7 th decade.

Barring one case aged 30 years where the whole of the intimal surface was calcified and ulcerated at places (Fig. 2) the calcified lesions were observed in $3 \mathrm{rd}$ decade but accounting $0.7 \%$ of the surface area. Later on a very slow increase in the surface involved by complicated lesion was noticed reaching to a maximum of $5.5 \%$ in 7 th decade. 


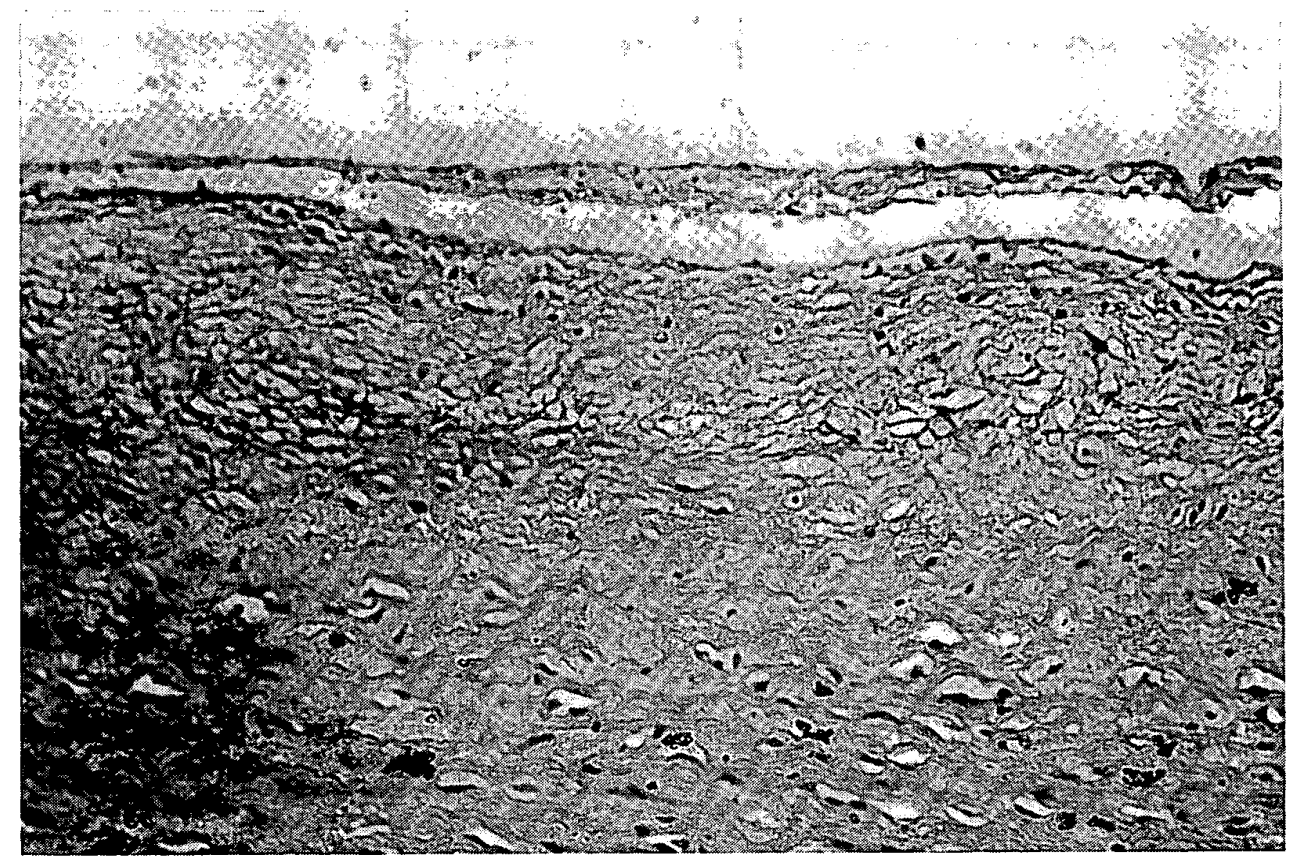

Fig.4. Fully developed fatty streak. H.\& E. X 100 .

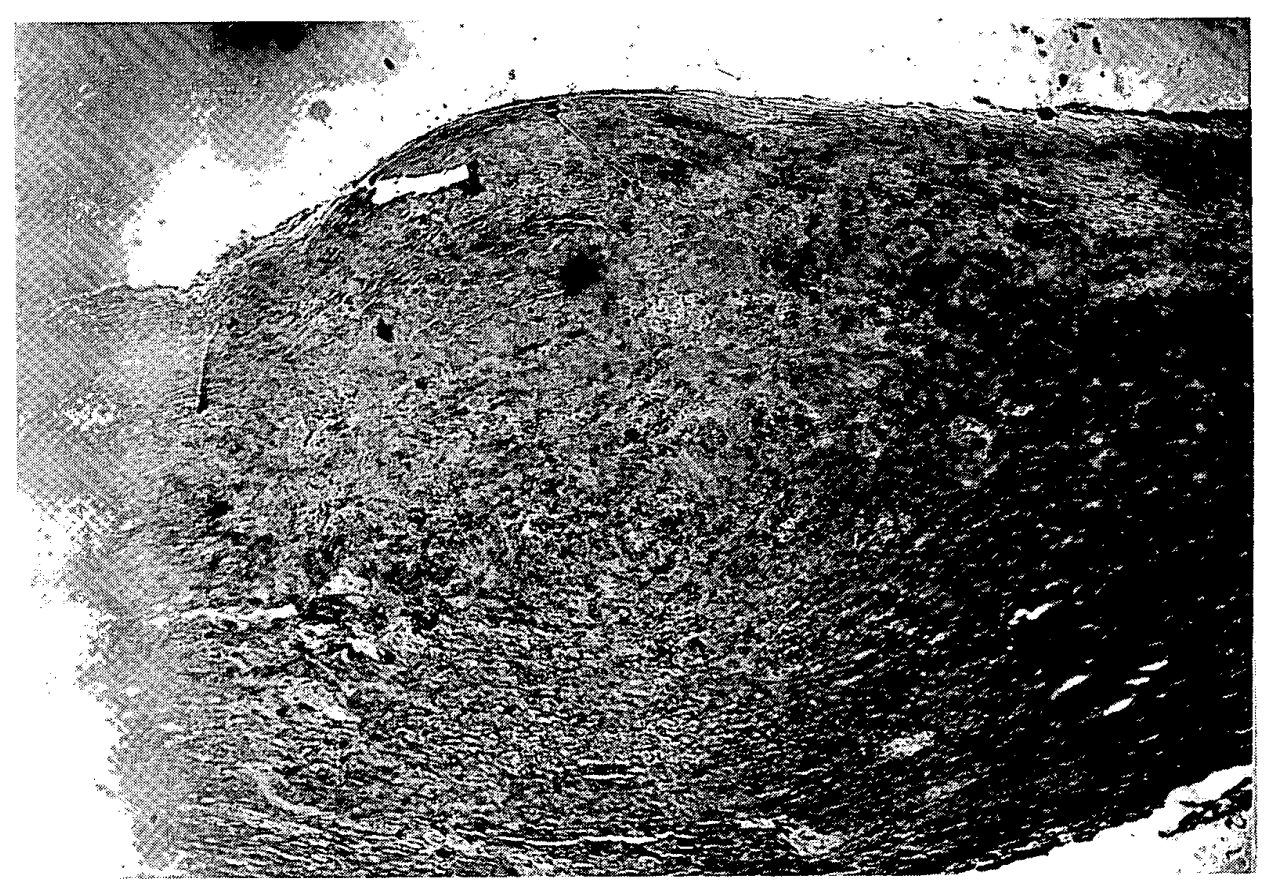

Fig.5. Atheromatous plaque showing fibrosis and loss of elastic fibres. Verhoeff's Stain $\times 25$.

Atheromatous lesions around the coronary ostia were observed in $23.6 \%$ specimens.

\section{Micro anatomic Features}

The earliest lesion or fatty streak was characterized by the presence of foamy cells in the subendothelial area, scanty round cell infiltration, oedema and basophilic staining of the ground substance and attenuation of elastic fibres. In some areas the lesion was raised from the surface (Fig. 3). The fully developed fatty streaks showed deposition of extracellular fat in the form of cleft like spaces (cholesterol deposit) with a greater tendency of collagenisation specially in the deeper position (Fig. 4). Inflammatory cells were sparse. No deposition of fibrin was observed at this stage.

The fibrous plaque revealed a raised area of 


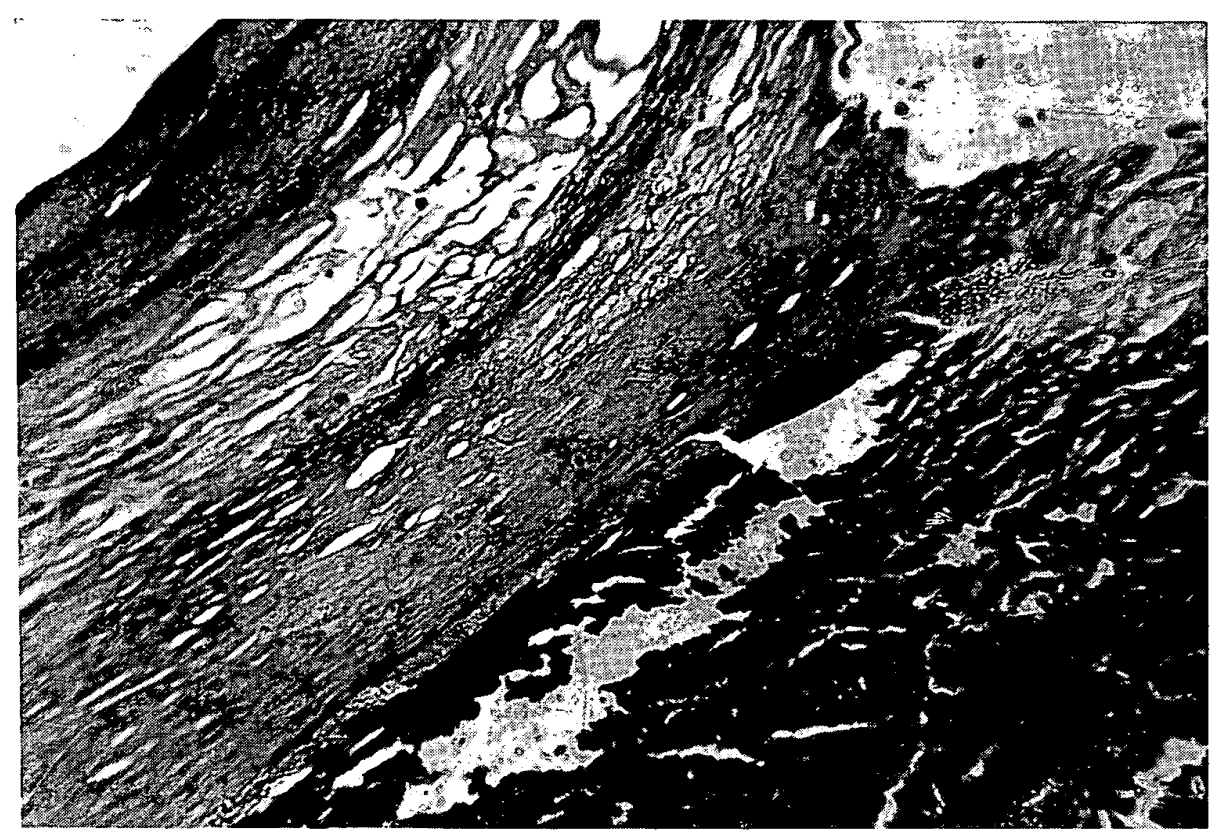

Fig.6. Different layers of fibrous cap and a big calcified mass in the deeper portion. H. \& E. $\times 50$.

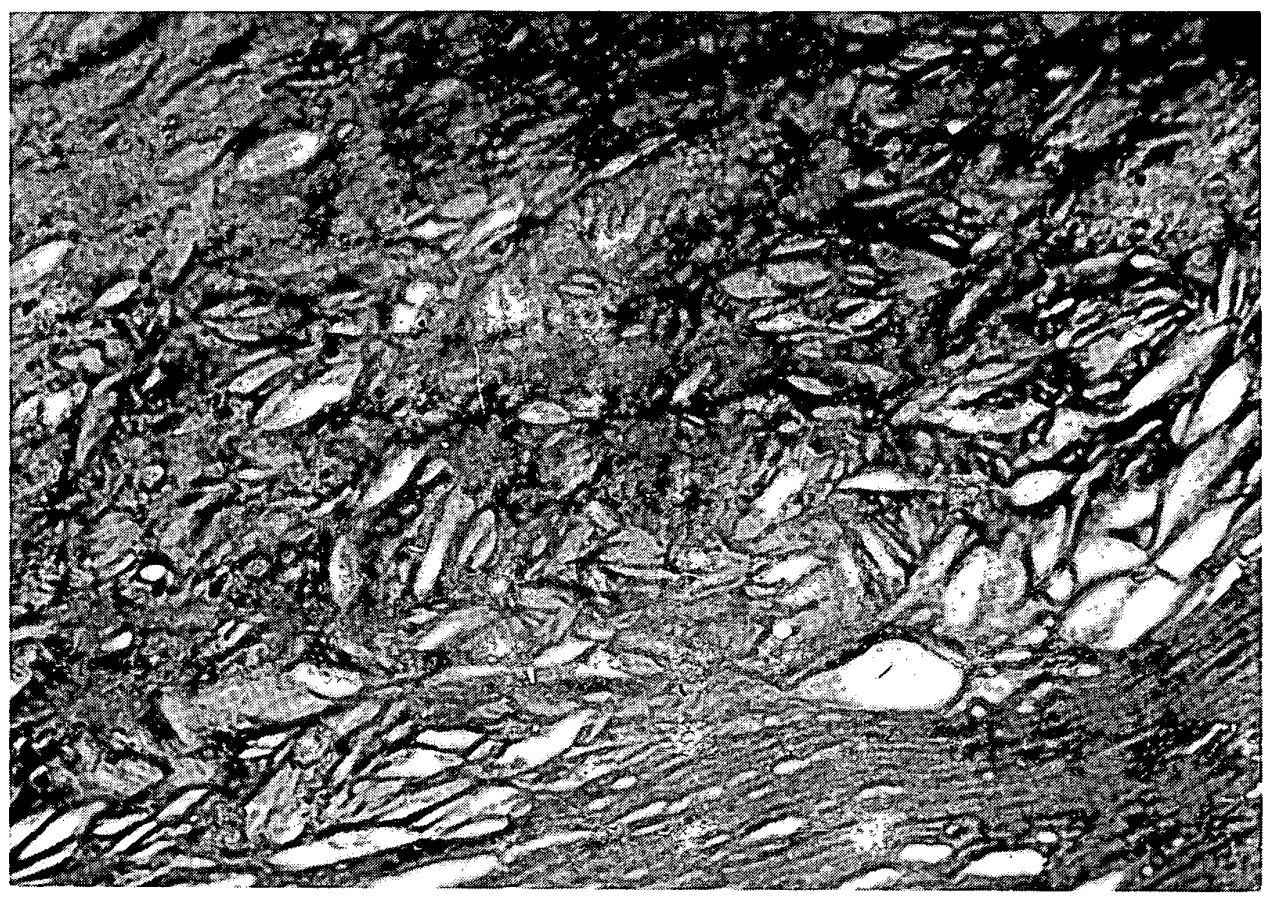

Fig.7. Cholesterol clefts in the deeper portion of atheromatous lesion. H. \& E. $\times 160$.

hyaline connective tissue enclosing a mass of extracellular lipid material (Fig. 5). Though still situated in the subintimal region it was generally not well demarcated from the media. The deeper sclerotic portion of the plaque was extending into the media resulting into loss of internal elastic lamina.

The superficial fibrous cap generally comprised of two to four distinct layers indicating desmoplastic activity occurring at different stages of development of the lesion (Fig. 6). Cholesterol clefts (Fig. 7) were, however, very prominent at places. Vascularisation of fibrous plaque was seen in $18.6 \%$ lesions, characterized by cleft like spaces lined by endothelial cells.

Calcification of atheromatous lesion was seen in $4.5 \%$ cases, generally occurring in the deeper portion of the lesion (Fig. 6) but at times whole 


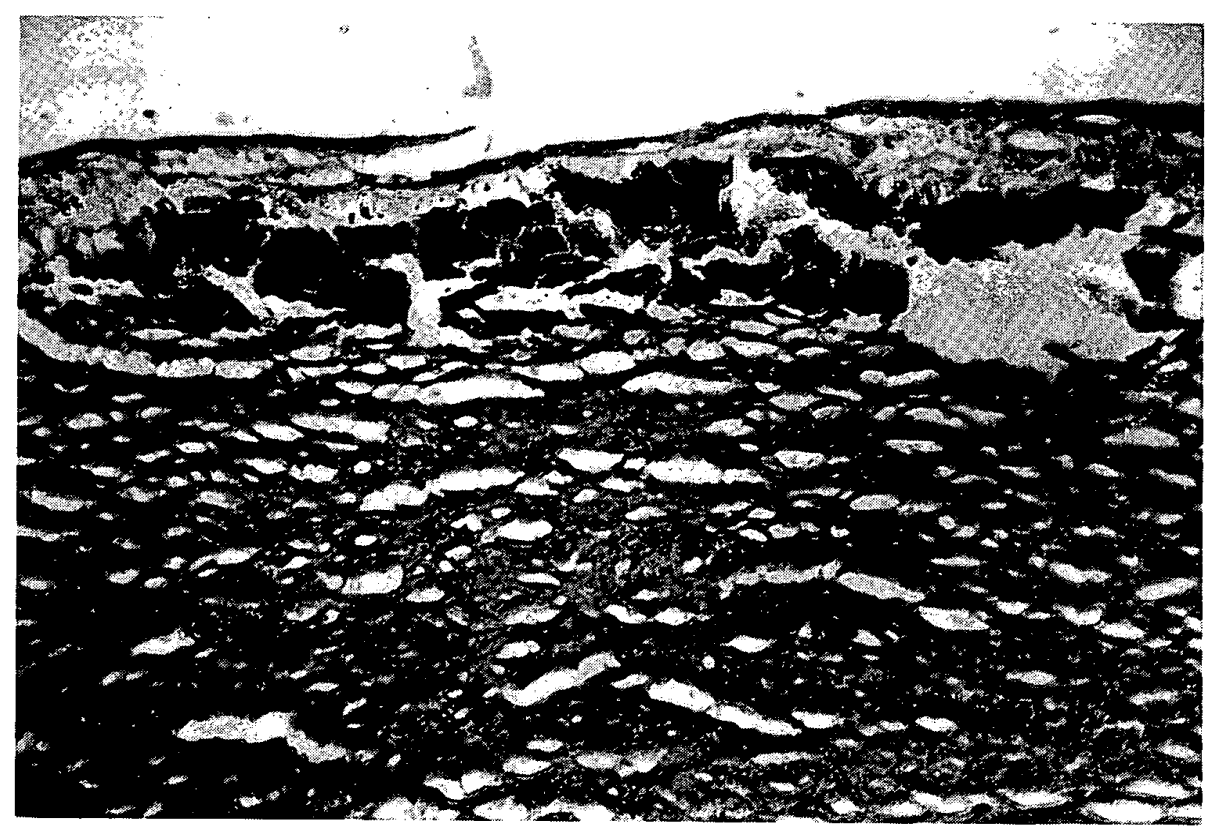

Fig.8. Calcification of entire superficial lesion. H. \& E. $\times 50$.

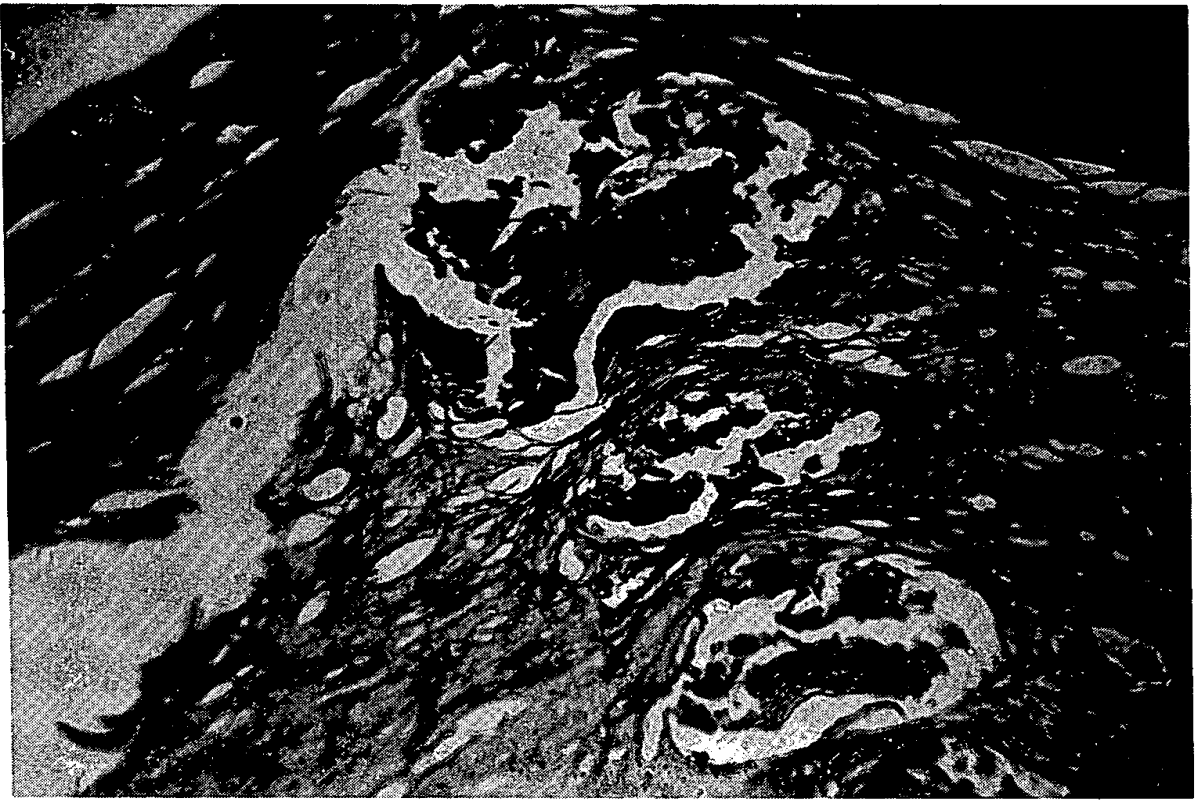

Fig.9. Incorporation of series of mural thrombi (only 4 seen) in the atheromatous lesion. H. \& E. $\times 50$.

of the superficial lesion was found to be calcified (Fig. 8). In this very case fatty streaks, fibrous plaque and partially or completely calcified lesions were observed in the same section. In case no. 102 where the wall was bony hard like an egg shell (Fig. 2) calcification was seen in the deeper as well as in the superficial portion. In another section from the same aorta multiple thrombi (6 in number) of varying size were observed lying one over the other. These con- tained pink homogenous mass (fibrin like material) in the centre (Fig. 9).

In media vascularisation was seen in 20 cases (18.2\%). No medial calcification was demonstrated in any section. The adventitia revealed congestion and mononuclear cell infiltration in 36 cases $(32.7 \%)$.

Unstained frozen sections when viewed under polarising microscope, depicted anisotropic birefringent cholesterol crystals. Fat globules could 


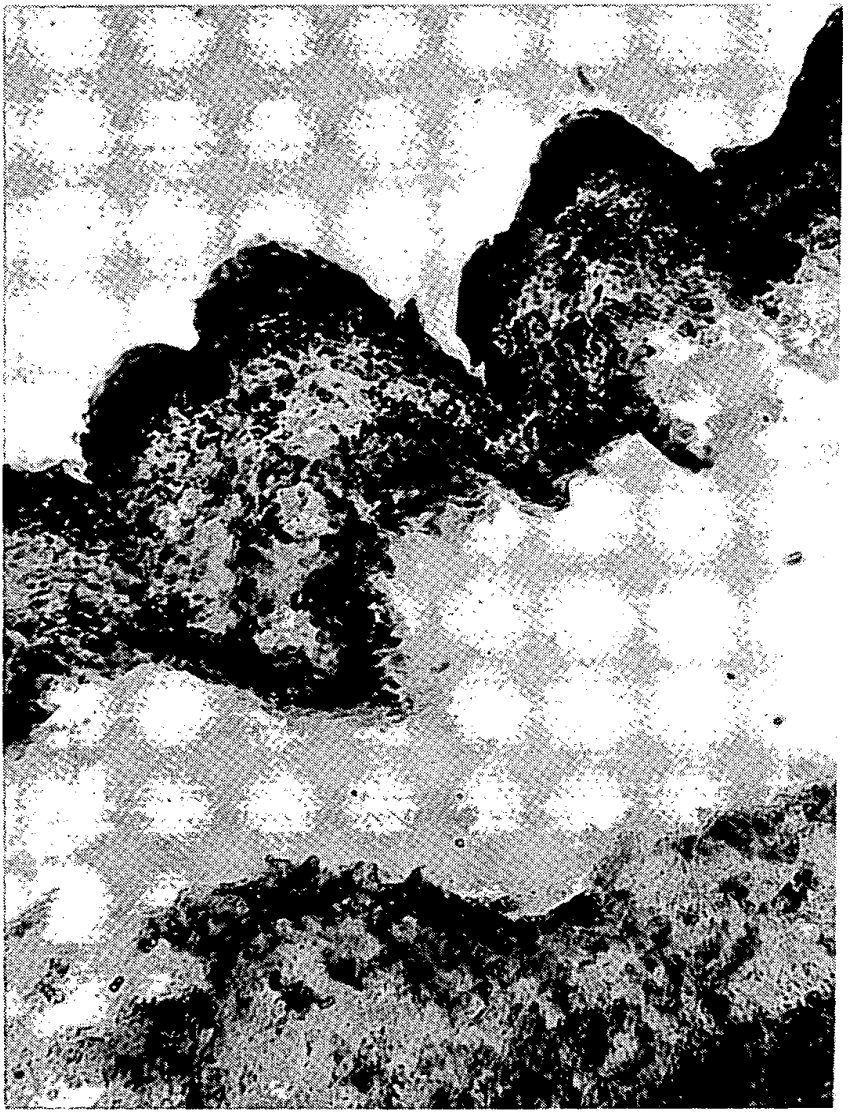

Fig.10. Fat in the subintimal area (Frozen Section). Sudan IV $\times 120$.

be demonstrated in the subintimal zone by staining the sections with Sudan IV (Fig. 10).

Thus the whole sequence in evolution of atheromatous lesion could be summarised as follows:

First of all there is accumulation of fat in the mesenchymal cells changing them into lipophages or foam cells. Later on the lipid becomes extracellular which causes the collaginisation of intima forming a fibrous hyalinised cap. Finally the lesion is calcified. Once the fibrous plaque is formed the further progression of the disease is caused by encrustation of intramural thrombi as had been observed in the present study (Fig. 9).

\section{DISCUSSION}

So far much work has been done regarding the incidence of atherosclerosis of aorta and it has revealed marked quantitative and qualitative differences in the various ethnic groups of the world!-3,6,11-13 Barring a few exceptions the incidence as well as the severity of atherosclerotic lesions was found to be increasing with the advanced age in the present series. This was in complete agreement with the observations of other Indian workers.6,12,14 Only Mukherjee and Tribedi ${ }^{1}$ have reported the involvement of different parts of aorta, the root of the aorta showing atherosclerotic lesions in $53.8 \%$ specimens. In the present study, however, the atherosclerosis was observed in $70 \%$ aortas. This was in close proximity to the observations of Nanvaty, et al. ${ }^{14}$ who have reported the involvement of $78 \%$ aortas.

The lesions at the root of aorta in 2 nd decade were observed in $25 \%$ specimens, quite contrary to the findings of Tejada and Gore ${ }^{11}$ and Nanavaty et $\mathrm{al}^{14}$ who have observed atherosclerosis in $72 \%$ and $94 \%$ specimens of entire aorta in 2nd decade. This showed that the root of aorta is less frequently involved at this stage as compared to other portions of the vessel.

The significant difference observed in Indians is the slow progression of fibrous plaques and the less frequency of the complicated lesions. This clearly shows that not all the fatty streaks progress to fibrous plaques. This has been well demonstrated by Hill et al ${ }^{15}$ that fatty streaks present in the early phase of the disease, may disappear altogether or remian as such (stationary) or may progress to fibrous plaque. What mechanism is involved in the progression of fatty streaks to plaques is still not clear. The fibrosis could be due to fibrin deposition ${ }^{16}$ or as a response to injury caused by extracellular deposition. ${ }^{17}$ The incidnece of fibrous plaques is definitely low in Indian population as observed in the present series as well as by other Indian works and also in the inhabitants of underdeveloped countires? $2,7,12$

The complicated lesions were rarely seen, involving a very small percentage of intimal surface (less than $1 \%$ in $3 \mathrm{rd}$ decade and $5.5 \%$ in 7 th decade). Now the question is why these lesions are so rare in Indians as compared to high involvement (above 40\%) in U.S.A., Japan and Jamaica? The only possibility could be the decreased tendency of thrombus formation.,18

As reported earlier ${ }^{19}$ no correlation was obtained between the incidence and severity of the atherosclerotic lesions occurring at the root of aorta and those in the coronary artery. One could see severe atherosclerotic lesion in one vessel while the other may be free from the disease or have only early lesions. It is difficult to explain this disparity - only possibility could be the susceptibility of individual vessel towards atheromatous lesion. 


\section{Acknowledgement}

The authors are grateful to Mr. S. Mujeer, Chief Photographic Technical Assistant for the photographs presented.

\section{REFERENCES}

1. MUKHERJEE, A. B. \& TRIBEDI, B. P.: Atheromatous lesions in Bengal: Observations on 4000 unselected autopsies. J. Indian Med. Ass. 12: 285$290,1943$.

2. HIRST, A. E., GORE, I., HADLEY, G. G., \& GAULT, E. W.: Gross estimation of atherosclerosis in Aorta, coronary and cerebral arteries. A comparative study in Los Angeles and South India. Arch. Path. 69: 578-585, 1960.

3. GORE, I., ROBERTSON, W. B., HIRST, A. E., HADLEY, G. G., \& KOSEKI, Y.: Geographic differences in the severity of Aortic and coronary atherosclerosis. Am. J. Path. 36: 559-574, 1960.

4. MATHUR, K. S. \& KUMAR, V.: Natural history of aortic atherosclerosis. J. Indian Med. Ass. 39: $415-418,1962$.

5. RESTREPO, C., STRONG, J. P., \& McGILL, H. C.: The natural history of aortic and coronary atherosclerosis in Columbia Evaluated by necropsy examination. J. Atheroscler. Res. 4: 213-219, 1964.

6. TANDON, H. D., KARMARKAR, M. G., GUPTA, P. K., \& RAMALINGASWAMI, V.: Morphogenesis of aortic and coronary atherosclerosis in North India - a composite study. Exp. Mol. Path. 9: $293-308,1968$.

7. TEJADA, C., GORE, I., STRONG, J. P., \& McGILL, H. C.: Comparative severity of atherosclerosis in Costa Rica, Guatemala and New Orleans. Circulation 18: 92-97, 1958.

8. TEJADA, C., STRONG, J. P., MONTENEGRO, M. R., RESTREPO, C., \& SOLDBERG, L. A.: Distribution of coronary and aortic atherosclerosis by geographic location, race and sex. Lab. Invest. 18: $509-526,1968$.

9. CRAWFORD, T.: Pathology of Ischaemic Heart
Disease. 1st Ed. London, Butterworths, 1977, p. 29.

10. HOLMAN, R. L., McGILL, H. C., STRONG, J. P., \& GEER, J. C.: Technics for studying atherosclerotic lesions. Lab. Invest. 7: 42-27, 1958.

11. TEJADA, C. \& GORE, I.: Comparison of atherosclerosis in Guatemala City and New Orleans. Am. J. Path. 33: 887-894, 1957.

12. MURTHY, M. S. N., DUTTA, B. N., \& RAMALINGASWAMI, V.: Aortic atherosclerosis in North India (Delhi area). J. Path. Bact. 83: 135-142, 1962.

13. TANDON, H. D., DUGGAL, K., \& RAMALINGASWAMI, V.: Atherosclerosis of the aorta in North India (Delhi area). The established lesions. Indian J. Path. \& Bact. 13: 125-130, 1970.

14. NANAVATY, M. P., JHALA, C. I., \& MATHUR, B. B.: Atherosclerosis of renal artery and its comparative study with aortic atherosclerosis. Indian J. Path. \& Bact. 11: 160-165, 1968.

15. HILL, K. R., CAMPS, F. E., RIGG, K., \& McKINNEY, B. F.: Atherosclerosis: Results of a pilot survey in a north London area. Brit. Med. J. 1: $1190-1192,1961$.

16. MOVAT, H. Z., HAUST, M. D., \& MORE, P. H.: The morphologic elements in the early lesions of atherosclerosis. Am. J. Path. 35: 93-102, 1959.

17. FRENCH, J. E.: Chapter XIII. "Atherosclerosis" in 'General Pathology' edited by Lord Florey. 4th Ed. Londond, LLoyd Luke (Medical Books) Ltd., 1970. p. 577.

18. GOODALE, F., LEE, K. T., SCOTT, R. F., EDINGTON, G. M., SNELL, E. S., \& DAVIES, J. N. P.: Geographic Pathology of Atherosclerosis. Study of disease patterns in autopsied individuals from Kampala, Uganda, Ibadan, Nigeria and Albamy, New York. Exp. Med. Path. 3: 148-164, 1964.

19. TYAGI, S. P., DADGAR, S. K., HAMEED, S., \& SINGH, R. P.: Coronary atherosclerosis in Aligarh District - A morphological study. Jap. Circul. J. 42: 10, 1978. 